\title{
Erratum
}

\section{Highlights of this issue, December 2018 - ERRATUM}

\author{
Derek K. Tracy
}

https://doi.org/10.1192/bjp.2018.254, Published by Cambridge University Press, 26 November 2018.

In the original version of these highlights, it was stated incorrectly that Derek K. Tracy was the author. In fact, the author of this piece was Kimberlie Dean. This change has been made to the original article online.

The publisher apologises for this error.
Derek K. Tracy

\section{Reference}

Tracy DK. Highlights of this issue. The British Journal of Psychiatry. Cambridge University Press; 2018;213(6):A47-A47. https://doi.org/10.1192/bjp.2018.254 